\title{
The cold-fingered carpenter: an uncommon cause of digital ischaemia
}

\author{
Michael J Plakke, Richard Alweis, Maryam Mahmood
}

Department of Internal Medicine, Reading Health System, West Reading, Pennsylvania, USA

\section{Correspondence to}

Dr Michael J Plakke, mjplakke@gmail.com
To cite: Plakke MJ, Alweis R, Mahmood M. BMJ Case Rep Published online: [please include Day Month Year] doi:10.1136/bcr-2013010317

\section{DESCRIPTION}

A 50-year-old male carpenter presented with 2 weeks of right index finger numbness and coolness. He noted that it occasionally appeared paler than his other fingers. In the 2 days prior to presentation, he noticed similar but milder symptoms in his right middle finger. The symptoms were minimal in the morning, but worsened throughout the day. He recently underwent repetitive trauma to his dominant (right) hand while laying flooring and forcing tiles into place using the ulnar side of his fist. He was a smoker but had no other significant medical history.

Initial physical examination findings included complete sensory deficit over the entirety of the right second digit and over the distal phalanx of the right third digit, with coolness and cyanosis of these areas.

Differential diagnosis included acute arterial thrombosis, atherosclerotic disease, thromboangiitis obliterans (Buerger's disease) and Raynaud's disease. He was first sent for an MR angiography (MRA).

MRA revealed a large aneurysm in the distal ulnar artery at its confluence with the superficial palmar arch (figure 1) and several areas concerning for thrombosis (figure 2). He was started on dual antiplatelet therapy (aspirin $81 \mathrm{mg}$ and clopidogrel $75 \mathrm{mg}$ daily) and referred to a vascular surgeon, who ordered a standard angiogram in preparation for the surgical reconstruction.

Digital subtraction angiography (DSA) was performed to better define the patient's arterial anatomy (figures 3 and 4 ) leading to the diagnoses of hypothenar hammer syndrome (HHS).

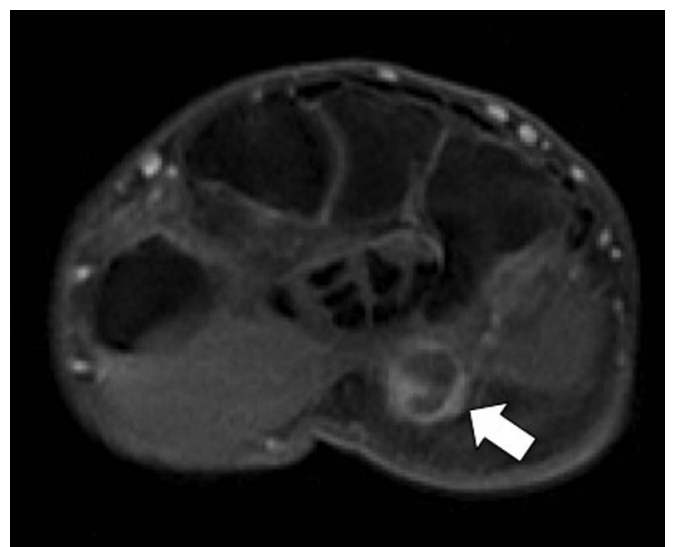

Figure 1 MRA, axial view-large, $11 \mathrm{~mm} \times 11 \mathrm{~mm}$ aneurysm in the distal ulnar artery, most consistent with the hypothenar hammer syndrome.

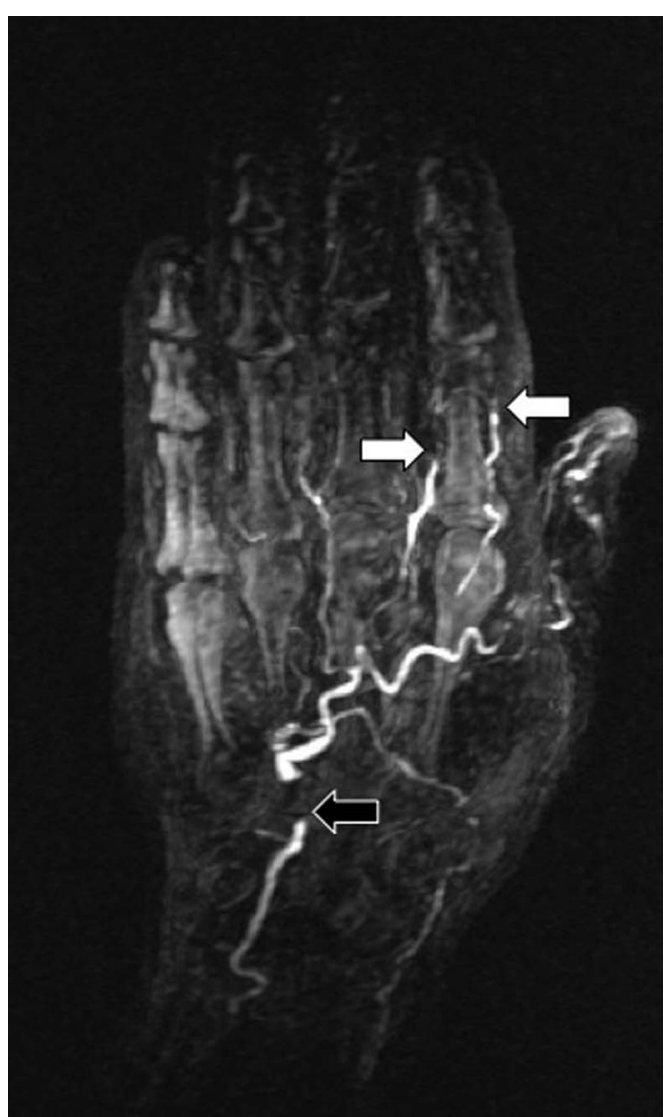

Figure 2 MRA, coronal view-two areas in the second proper digital arteries (white arrows) and one area in the distal ulnar artery (black arrow) demonstrate loss of signal intensity, prompting concern for thrombosis.

HHS is an uncommon cause of digital ischaemia predominantly diagnosed in male industrial workers who undergo repetitive hand trauma to the hypothenar eminence. ${ }^{1}$ The pathophysiology of HHS is attributable to the vulnerability of the distal ulnar artery as it courses through Guyon's canal between the hook of the hamate and the pisiform. ${ }^{2}$ The ulnar artery is afforded little protection in this area; repetitive microtrauma damages the arterial intima and predisposes the vessel to aneurysm and thrombosis. ${ }^{1} 2$ It most commonly presents with numbness and paraesthesia in the third, fourth and fifth digits. Diagnosis may be clinical, but is strongly supported by the imaging. Several imaging modalities have been described, but the angiography remains the gold standard. ${ }^{2}$ Treatment may be conservative, with combined therapy using antiplatelet agents and calcium channel blockers, or may involve a variety of surgical techniques. Thrombolysis may also be indicated for an acute onset digital ischaemia. $^{2}$ 


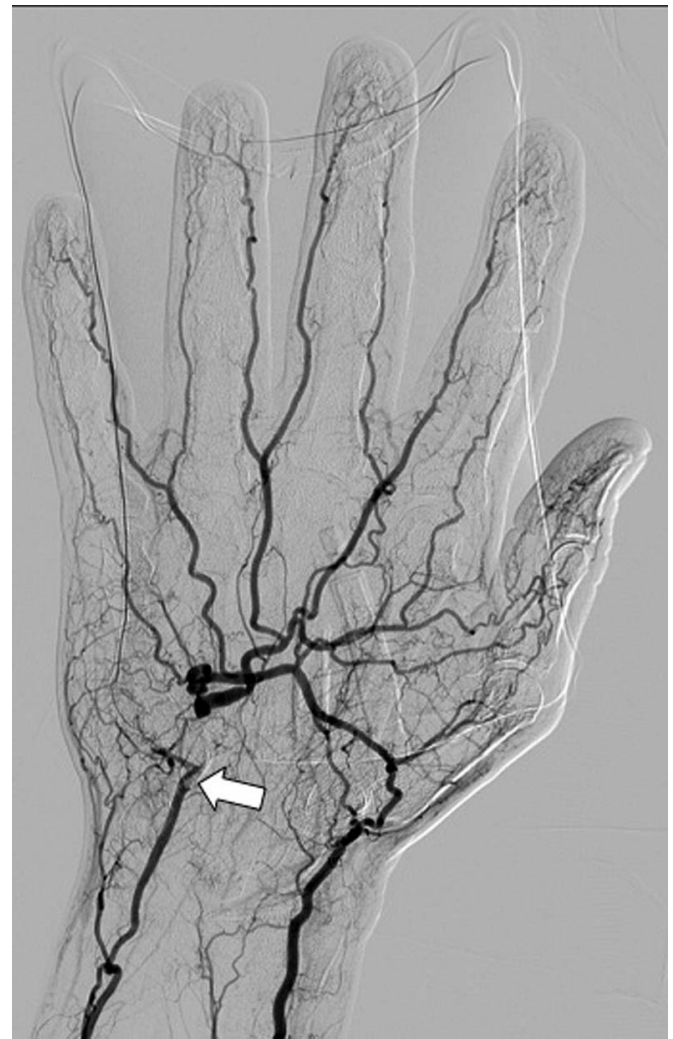

Figure 3 DSA-abrupt occlusion of the ulnar artery at the level of the hook of the hamate bone, with a very small, bilobed thrombus within the ulnar artery just central to the occlusion (arrow).

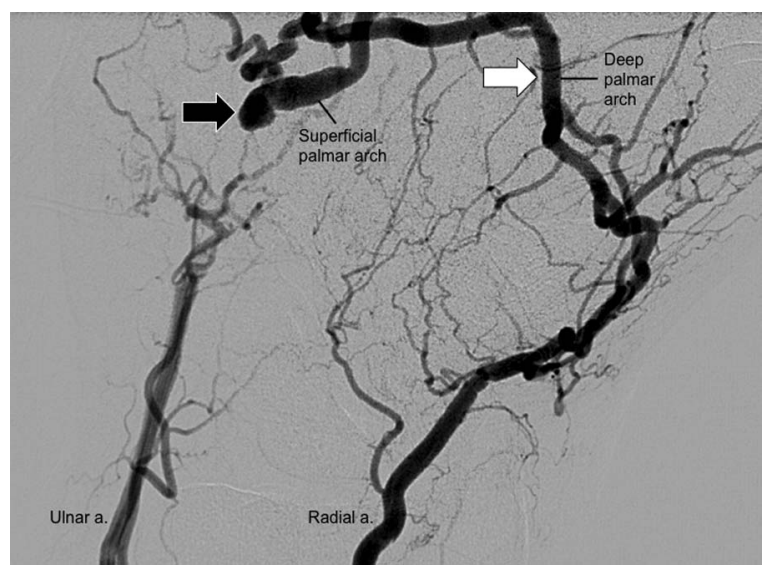

Figure 4 DSA, zoomed in-elongated aneurysm (20 mm in length, $6 \mathrm{~mm}$ in diameter) involving the distal ulnar artery and superficial palmar arch (black arrow) and hypertrophied deep palmar arch (white arrow) providing collateral flow.

\section{Learning points}

- Hypothenar hammer syndrome should be considered in all patients who undergo repetitive hand trauma and present with digital numbness and paraesthesia.

- Imaging workup is crucial in defining the presence of thrombosis and/or aneurysm and planning invasive procedures; standard angiography should be performed in the absence of contraindications.

Contributors All authors have approved the final article and can take responsibility for its content.

Competing interests None.

Patient consent Obtained.

Provenance and peer review Not commissioned; externally peer reviewed.

\section{REFERENCES}

1 Jose J, Dreizin D. Hypothenar hammer syndrome. Am J Orthop 2012;41:380-2.

2 Yuen JC, Wright E, Johnson LA, et al. Hypothenar hammer syndrome: an update with algorithms for diagnosis and treatment. Ann Plast Surg 2011;67:429-38. 
Copyright 2013 BMJ Publishing Group. All rights reserved. For permission to reuse any of this content visit http://group.bmj.com/group/rights-licensing/permissions.

BMJ Case Report Fellows may re-use this article for personal use and teaching without any further permission.

Become a Fellow of BMJ Case Reports today and you can:

- Submit as many cases as you like

- Enjoy fast sympathetic peer review and rapid publication of accepted articles

- Access all the published articles

- Re-use any of the published material for personal use and teaching without further permission

For information on Institutional Fellowships contact consortiasales@bmjgroup.com

Visit casereports.bmj.com for more articles like this and to become a Fellow 